Thi Hong Trinh Nguyen

\title{
Private International Law in Vietnam
}

On General Issues, Contracts and Torts in Light of European Developments

[Internationales Privatrecht in Vietnam - Eine Untersuchung über allgemeine Fragen,Vertrags- und Deliktsrecht vor dem Hintergrund europäischer Entwicklungen.]

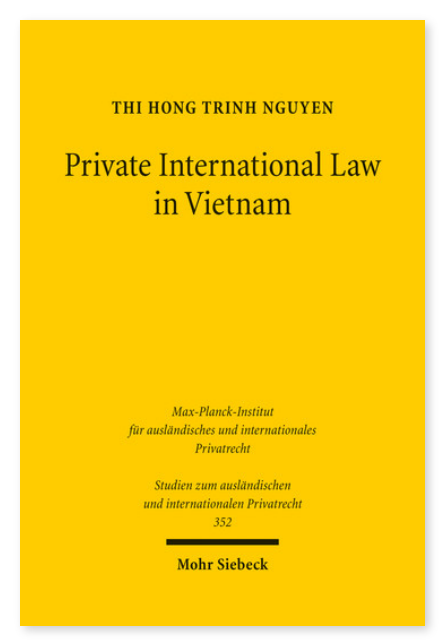

2016. XV, 264 Seiten. StudIPR 352

ISBN 978-3-16-154186-5

DOI 10.1628/978-3-16-154186-5

eBook PDF $69,00 €$

ISBN 978-3-16-154185-8

fadengeheftete Broschur 69,00€
Veröffentlicht auf Englisch.

Trinh Nguyen untersucht das Internationale Privatrecht Vietnams vor dem Hintergrund europäischer Entwicklungen. Sie beschreibt und bewertet gegenwärtige Regelungen im vietnamesischen Recht und die dazugehörige Gerichtspraxis. Anhand einer kritischen Auseinandersetzung mit der westlichen Rechtslehre macht sie Vorschläge für das zukünftige vietnamesische Recht.

Thi Hong Trinh Nguyen Born 1983; 2005 Bachelor of Law at Hue College of Sciences (Vietnam); 2010 Master's in Law with International Law Specialization at Hanoi Law School (Vietnam); 2011-15 doctoral candidate in Law at Hamburg University; presently lecturer in Private International Law, Hue University School of Law.

Jetzt bestellen:

https://mohrsiebeck.com/buch/private-international-law-in-vietnam-9783161541865?no_cache=1

order@mohrsiebeck.com

Telefon: +49 (0)7071-923-17

Telefax: $+49(0) 7071-51104$ 